\title{
Fabrication and Characterization of Nano MgO Crystal
}

\author{
Haicheng Wei ${ }^{1, a} \quad$ Lisheng Tang ${ }^{2, b} \quad$ Mingxia Xiao ${ }^{1, c} \quad$ Yajie $X u^{1, d}$ \\ ${ }^{1}$ School of Electrical and Information Engineering, Beifang University For Nationalities, Yinchuan, \\ Ningxia, China \\ ${ }^{2}$ Beijing Hui Feng Energy Technology Co., Ltd., Beijing, China \\ awei_hc@nun.edu.cn bxiao_xiao963@163.com 'xu_yj1991@163.com dtangtls@163.com
}

\begin{abstract}
In this work, the direct precipitation method was used to generate magnesium salt $\mathrm{Mg}(\mathrm{OH}) 2$, the process of preparing $\mathrm{MgO}$ crystal by calcining $\mathrm{Mg}(\mathrm{OH}) 2$ in three stage temperature was studied, and $\mathrm{MgO}$ crystal was characterized by scanning electron microscope and XRD. On this basis, the energy band structure and states density of Mgo crystal were calculated by the first principle theory, the influence of crystal orientation on Mgo secondary electron emission was analyzed. The experimental results show that the $\mathrm{MgO}$ prepared by this method is cubic crystal. The grain size is evenly distributed in the vicinity of $40.65 \mathrm{~nm}$. The crystal orientation is of (200), (111), (220) and along the (200) orientation preferential growth.
\end{abstract}

Keyword: MgO Crystal, Secondary Electron Emission, First Principle theory, Direct Precipitation Method

\section{Introduction}

$\mathrm{MgO}$ is a kind of metal oxide material, which has capacities of good insulation, chemical inertness and sputtering resistance. Since $\mathrm{MgO}$ has the factors of high coefficient of secondary electron emission, stable working performance, can withstand high current density, craft process simple, it is widely used as materials secondary electron emitter. It is important component of optoelectronic detecting instruments and flat panel display devices [1]. In the related research field, $\mathrm{MgO}$ can be used as the dielectric protective film material of the gas discharge device[2], and the improvement of the surface electron emission ability has become the key factor to improve the luminous efficiency of the device [3][4]. It is important to study the preparation technology of $\mathrm{MgO}$ material in high Xe environment, which can increase the number of secondary electron emission on the surface of $\mathrm{MgO}$ material and improve the luminous efficiency of the device [5].

But there are some problems come out with the increase of Xe content in the working gas of $\mathrm{MgO}$, such as the increase of discharge delay and the decrease of the response speed of the device. $\mathrm{Kim}$ et al. study on the effects of the exo-electron on $\mathrm{MgO}$ materials for addressing speed, put forward by increasing the number of the exo-electron methods to improve addressing speed [6]. Because of the high specific surface of nano $\mathrm{MgO}$ crystal by using microcrystalline particles, the exo-electron emission quantity will be improved, the speed of electron emission will be accelerated, the discharge delay time will be reduced, the stability of discharge will be improved. Therefore, it is very important to fabricate the high purity and consistency $\mathrm{MgO}$ particles for improving the electron emission characteristics of optoelectronic devices.

In this paper, the microstructure of $\mathrm{MgO}$ crystal was studied, and the precursor of $\mathrm{MgO}$ was prepared by low cost liquid phase synthesis method. The preparation process of nano $\mathrm{MgO}$ crystal material was explored, which could guide the preparation of $\mathrm{MgO}$ material. The related research has 
a theoretical and practical significance for understanding the relationship between the microstructure of $\mathrm{MgO}$ materials and the electron emission coefficient.

\section{Theory of MgO exo-electron emission}

General MgO primitive cell model could consult Sasaki's studies [7]. According to the reference, $\mathrm{MgO}$ has the same cubic cell structure as $\mathrm{NaCl}$, which belongs to the space group FM-3M. Standard $\mathrm{MgO}$ model contains $14 \mathrm{Mg}^{2+}$ and $13 \mathrm{O}^{2-}$, shown as Fig 1

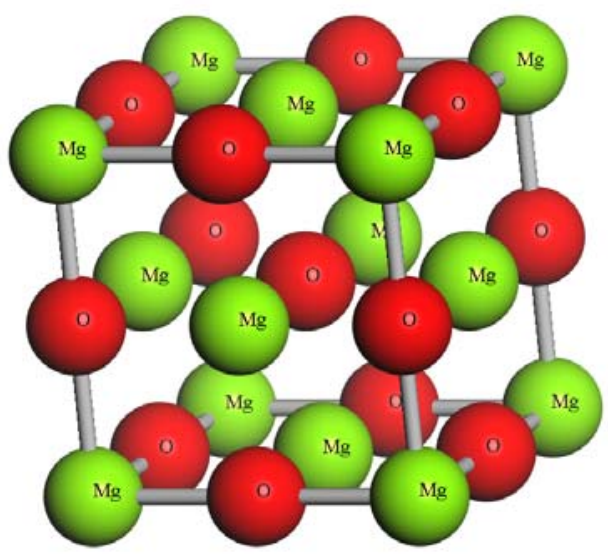

Fig. 1 Nano Mgo primitive cell model

Inside nano $\mathrm{MgO}$, the relaxation of electrons and holes, composite process that is captured by the forbidden band of electron in absorbing composite process of energy released from the surface of the $\mathrm{MgO}$ style after injection. This escape electron emission belongs to $\mathrm{MgO}$ material itself or into electrons and holes of $\mathrm{MgO}$ style after a slow delay compound produced by the electron emission. The main processes of escape electron emission of nanometer $\mathrm{MgO}$ style crystal are:

1) Electron irradiation in vacuum ultraviolet or electron collision excitation to the conduction band; 2) Shallow hole level can capture these electrons; 3) Captured through thermal excitation effect to be excited to conduction band again, and after drift in $\mathrm{MgO}$ style crystal, was captured by the hole again; 4) Radiation centers capture some electronic drift; 5) Electron in the band gaps by VUV irradiation or auger effect to the excitation energy to the discharge space form the run-up to erase the wall charges required.

Cathode electron excitation spectra showed that nano $\mathrm{MgO}$ crystal material itself has an oxygen defect in $\mathrm{MgO}$ crystal and a broad peak related to near $400 \mathrm{~nm}$ wavelength. Single crystal $\mathrm{MgO}$ particles in electron and ultraviolet photon excitation, will have two peaks near $400 \mathrm{~nm}$ and $235 \mathrm{~nm}$. The emission peaks exist in single crystal $\mathrm{MgO}$ particles, and luminous summit increases will increase with the size of $\mathrm{MgO}$ single crystal. The emission peak is mainly composed of the Auger recombination process of electron and hole in the composite produced by $235 \mathrm{~nm}(5.3 \mathrm{eV}) \mathrm{VUV}$. In the single crystal $\mathrm{MgO}$, the hole and electron recombination process, which can make the electrons in the forbidden band escape into the discharge space, can enhance the electron emission properties of the $\mathrm{MgO}$ materials

Therefore, Yan team [9][10] and Chiang[11] and others believe that the existing electronic single crystal $\mathrm{MgO}$ nano particles in the composite hole trap can produce desired electron and hole. Nano $\mathrm{MgO}$ crystal coating on the surface of $\mathrm{MgO}$ film, can increase the exo-electron emission surface, improve the low bit delay, improve the discharge stability. The preparation of nano $\mathrm{MgO}$ has an important significance for improving the photoelectric properties of $\mathrm{MgO}$ materials. 


\section{Fabrication method of nano MgO crystal}

The preparation of $\mathrm{MgO}$ nano particles with high purity was divided into $\mathrm{MgO}$ precursor preparation and $\mathrm{MgO}$ crystal preparation. In this paper, the precursor $\mathrm{Mg}(\mathrm{OH})_{2}$ was prepared by direct precipitation method, and the $\mathrm{MgO}$ crystal was prepared by calcination method [12].

Fabrication of $\mathrm{Mg}(\mathrm{OH})_{2}$

Morphology of prepared $\mathrm{MgO}$ precursor $\mathrm{Mg}(\mathrm{OH})_{2}$ was influence on the following morphology of $\mathrm{MgO}$ crystal in a certain extent. The precursor crystal morphology, size and crystal orientation related by the technics of preparation. It is necessary to consider the process parameters in the preparation process.

The experiment mainly adopts magnesium salt $\mathrm{C}_{4} \mathrm{H}_{6} \mathrm{O}_{4} \mathrm{Mg} \cdot 4 \mathrm{H}_{2} \mathrm{O}$, using $\mathrm{NaOH}$ as precipitant, selection of ethylene glycol as dispersing agent, to preparation of $\mathrm{Mg}(\mathrm{OH})_{2}$. The experiment was prepared by direct precipitation method, mainly studied in the process of preparation of magnesium salt and precipitant concentration on precursor shape looks and the influence of particle size.

When the precipitant concentration increased from $0.25 \mathrm{M}$ to $1.25 \mathrm{M}$, the reaction in direct precipitation under ultrasonic condition, the $\mathrm{Mg}(\mathrm{OH})_{2}$ shape changed from flake into rod gradually. When the initial concentration of magnesium salt increased from $0.4 \mathrm{M}$ to $0.8 \mathrm{M}$, the $\mathrm{Mg}(\mathrm{OH})_{2}$ particle size increases gradually, grain boundaries become blur, shown in Fig. 2.

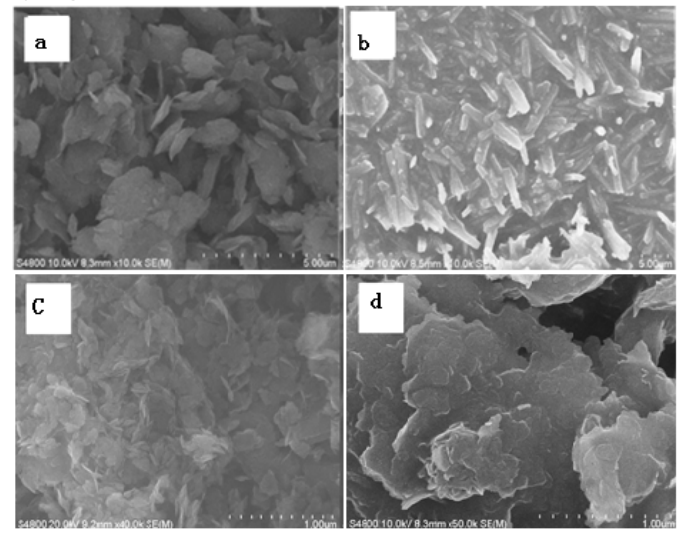

Fig.2 Photos of Different preparation magnesium hydroxide precipitant and the initial concentration of magnesium salt SEM (a: precipitation agent $0.25 \mathrm{M}$; b: precipitation agent $1.25 \mathrm{M}$; c: magnesium salt $0.4 \mathrm{M}$; d: precipitation agent $0.8 \mathrm{M}$ )

The reasons affecting the reactant concentration on the morphology and size of the precursor body are: there are two stages nucleation and grain growth of grain growth. If the concentration of reactants is too low, it is difficult to form a large number of homogeneous nucleation, grain will growth on the nucleation which has been formed priority, which makes easy to get great number of grain. When the concentration of reactants is too high, crystal nucleation rates greater than the growth rate, add with reactants produce a large number of crystal nucleus instantly, nucleus grew up too late, so the surface free energy is very high, it is easy to agglomerate. Therefore, when the precipitant concentration of $\mathrm{Mg} 2+$ is relatively large at the beginning time, degree of super saturation is great, and the nucleation rate is greater than the growth rate, it is easy to get small solids precipitation. But when the nucleation density is too large, it will lead to the blurring of the boundaries between the grains.

Fabrication of nano $\mathrm{MgO}$ crystal

$\mathrm{MgO}$ was prepared by three stage calcination heating process, and the $\mathrm{MgO}$ crystal was prepared by calcination of $\mathrm{Mg}(\mathrm{OH})_{2}$ with temperature control, and the calcination process can be described as formula (1).

$$
\mathrm{Mg}(\mathrm{OH})_{2} \stackrel{900^{\circ} \mathrm{C}}{\longrightarrow} \mathrm{MgO}+\mathrm{H}_{2} \mathrm{O} \uparrow
$$


In response, in order to ensure the crystal morphology and grain size of $\mathrm{MgO}$ crystal, the calcination process of experiment in environmental samples under nitrogen atmosphere, heating up to $1350^{\circ} \mathrm{C}$, the heating rate is $5^{\circ} \mathrm{C} / \mathrm{min}$, and set the temperature control heating curve according to the TG standard drawing precursor.

There are three heating temperature control curve, corresponding to the sample area. The multi segment weight loss, weight loss rate of sample temperature peak occurred at $340 \sim 427^{\circ} \mathrm{C}$, the temperature of the sample. The weight loss rate is $20.82 \%$. High loss rate showed that $\mathrm{Mg}(\mathrm{OH})_{2}$ is under this temperature decomposition. In addition, the weight loss of. $355^{\circ} \mathrm{C}$ belongs to the decomposition of organic matter caused by weightlessness temperature near the point of 709.3 $778.2^{\circ} \mathrm{C}$ also has $10.07 \%$. Since then, the highest temperature point control reaction heat treatment at $1156^{\circ} \mathrm{C}$, can reduce the surface defects of crystal grain, and the grain size of material, crystal etc. Finally, when the temperature rises to $1346.5^{\circ} \mathrm{C}$, the residual $\mathrm{MgO}$ mass is about $62.62 \%$, and the specific process is shown in Fig. 3.

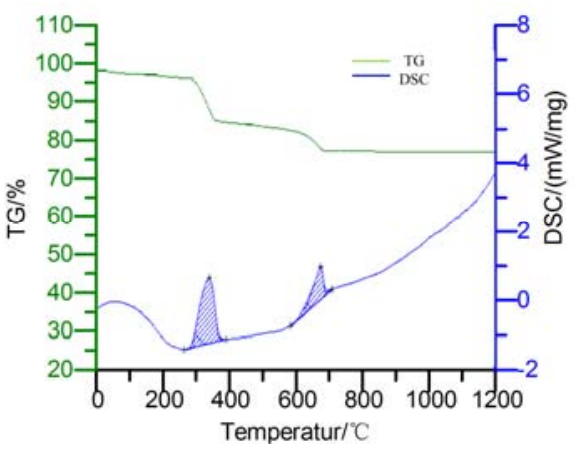

Fig $3 \mathrm{Mg}(\mathrm{OH})_{2}$ calcined hot weight standard

In the calcination experiments, The morphology of precursor can extent affect the shape of $\mathrm{MgO}$ style after calcining, flake of precursor will become cube morphology of $\mathrm{MgO}$ after calcining, rod-shaped precursor still keeps stick style of $\mathrm{MgO}$ after calcination. This is mainly because the precursor sheet can provide a good atmosphere, calcination process of crystallization is more uniform. And for the long rod precursor, crystal growth will be preferred in some direction in calcination.

In addition, the pretreatment of precursor will also affect the purity of crystal MgO. The $\mathrm{Mg}(\mathrm{OH})_{2}$ was cleaned and purified several times, and the experimental results show that the increase in the number of cleaning will removing impurities and increase the purity of nano $\mathrm{MgO}$ crystal, shown in Tab 1.

Tab1 The purity of $\mathrm{MgO}$ prepared by different processing

\begin{tabular}{ccccccc}
\hline \hline & \multicolumn{5}{c}{ Content of elements in $\mathrm{MgO}(\%)$} \\
Processing & $\mathrm{C}$ & $\mathrm{Na}$ & $\mathrm{Si}$ & $\mathrm{S}$ & $\mathrm{Ca}$ \\
\hline Clearing 5 & 0.32 & 0.014 & 0.03 & 0.014 & 0.026 \\
& & & & & \\
Clearing 7 & 0.2 & $<0.005$ & 0.0070 & 0.010 & 0.0050 \\
\hline \hline
\end{tabular}

\section{Character of nano MgO Crystal}

The $\mathrm{MgO}$ crystal was analyzed by scanning electron microscopy (SEM), and it is found that sheet $\mathrm{Mg}(\mathrm{OH})_{2}$ will formed cube structure $\mathrm{MgO}$ crystal powder after calcined. The crystallization and grain size of the powder is with expectations, as shown in Fig 4. 


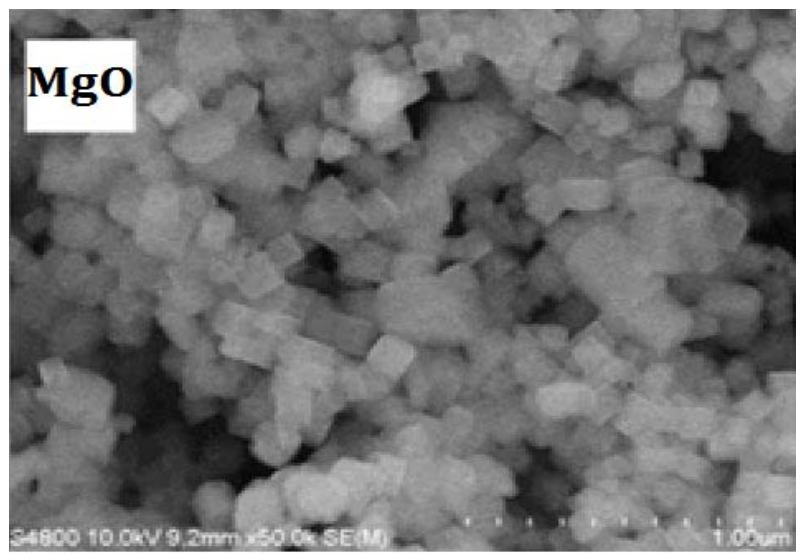

Fig.4 SEM of $\mathrm{MgO}$ formed by calcination of sheet $\mathrm{Mg}(\mathrm{OH})_{2}$

The analysis of crystal X-ray diffraction (XRD) preparation showed that the test data are fit the date of standard cubic test card (JCPDS87-0653 space groups Fm 3m). Under the condition of the corresponding process, the powder of $\mathrm{MgO}$ style is cube structure, the grain size at $2 \theta=36.937^{\circ}$, $42.917^{\circ}, 62.304^{\circ}, 74.691^{\circ}, 78.630^{\circ}$ appear diffraction peaks at (111), (200), (220), (311), (222), the diffraction peak is sharp, except for slight instrument test migration, no phase diffraction peaks exist. The results show that the $\mathrm{MgO}$ crystal has high purity, good crystallinity and crystal growth along (200), and the results are shown in Fig 5.

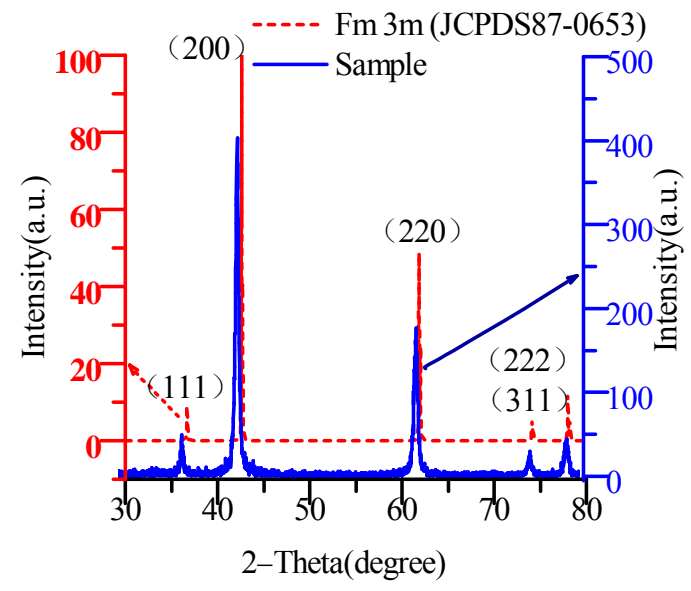

Fig.5 XRD test results of nano crystalline $\mathrm{MgO}$ structure

Get $\mathrm{MgO}$ data obtained by the above XRD test into the Scherrer formula, you can estimate the size of the grain, shown in Figure (2).

$$
D=\frac{K \lambda}{\beta \cos \theta}
$$

In the formula, the constant $\mathrm{K}$ is $0.943, \mathrm{D}$ is the average thickness of the grain is perpendicular to the plane direction, $\beta$ is the half height breadth of the samples' diffraction peaks, $\theta$ is diffraction angle, $X$-ray wavelength is $0.154056 \mathrm{~nm}$.

From the results of this experiment, $\beta$ is $0.22 \mathrm{~nm}, \theta$ is $21.46^{\circ}$, estimated grain size is $40.65 \mathrm{~nm}$. As described in the reference, the results which $\mathrm{MgO}$ style is cubic grain and the grain size distributed in the range of $50 \mathrm{~nm}$ are approximate.

\section{Conclusion}

Nano MgO crystal has the larger specific surface area, the higher the exo-electron emission characteristics, It has wider application. The preparation of $\mathrm{MgO}$ precursor using low cost solution, 
and the calcination process of preparation of $\mathrm{MgO}$ is an important method for the preparation of $\mathrm{MgO}$ crystal.

The $\mathrm{Mg}(\mathrm{OH})_{2}$ was prepared by direct precipitation in this article, the multistage calcination temperature control sheet was adopted to prepare $\mathrm{MgO}$ style crystal precursor, finally got $\mathrm{MgO}$ crystal orientation at (111), (200), (220), (311), (222). Experimental results show that the crystal orientation selective extension at (200), grain size is $40.65 \mathrm{~nm}$, showing a high degree of crystallinity.

\section{Acknowledgment}

This work is supported by the National Natural Science Foundation(No. 61461001).

\section{References}

[1] Weber Boeuf J. Plasma display panels: physics, recent developments and key issues[J]. Journal of physics D: Applied physics, 2003, 36 (6): R53-R57.

[2] Yan Q, Deng X, Lu Z, et al. 44.1: Invited Paper: High Luminous Efficacy PDP Using CaMgO Protecting Layer[C]. L.A. USA: SID, 2011:633-636.

[3] $\mathrm{Ha} \mathrm{CH}$, Kim JK, Whang KW. The role of the defect levels in $\mathrm{MgO}$ in the low firing voltage, wide driving voltage margin operation of an alternate current plasma display panel[J]. Journal of applied physics, 2007, 101 (12): 123301.1-123301.5.

[4] Li Yongdong, Yang Wenjing, Zhang Na, et al. A combined phenomenological model for secondary electron emission[J]. Acta Physica Sinica, 2013, 62 (7): 77901.1-7.

[5] Kim JS, Yang JH, Kim TJ, et al. Comparison of electric field and priming particle effects on address discharge time lag and addressing characteristics of high-Xe content AC PDP[J]. Plasma Science, IEEE Transactions on, 2003, 31 (5): 1083-1090.

[6] Sasaki S, Fujino K, Takéuchi Y. X-ray determination of electron-density distributions in oxides, $\mathrm{MgO}, \mathrm{MnO}, \mathrm{CoO}$, and $\mathrm{NiO}$, and atomic scattering factors of their constituent atoms.[J]. Proceedings of the Japan Academy Ser B Physical \& Biological Sciences, 1979, 55(2):43-48.

[7] Li Qiaofen, Tu Yan, Yang Lanlan,et al. First Principle Calculation of Exciton Binding Energy in $\mathrm{MgO}[\mathrm{J}]$. Chinese Journal of Vacuum Science and Technology, 2013, 33(10):1042-1046.

[8] Kuang W J, Li Q, Chen Y X, et al. Surface exciton emission of MgO crystals[J]. Journal of Physics D Applied Physics, 2013, 46(36):510-516.

[9] Yan Q, Deng X, Lu Z, et al. 44.1: Invited Paper : High Luminous Efficacy PDP Using CaxMg1-x O Protecting Layer[J]. Sid Symposium Digest of Technical Papers, 2011, 42(1):633-636.

[10]Chiang C L, Zeng H K, Li C H, et al. Secondary electron emission characteristics of oxide electrodes in flat electron emission lamp[J]. Aip Advances, 2016, 6(1):091501-555.

[11]Liu Tao, Ma Pengcheng, Yu Jingkun, et al. Preparation of MgO by Thermal Decomposition of $\mathrm{Mg}(\mathrm{OH}) 2[\mathrm{~J}]$. Journal of the Chinese Ceramic Society, 2010, 38(7): 1337-1340.

[12]LF. The race for TVs with higher luminous efficiency[J]. Advanced Display, 2007, 7: 23-29. 